\title{
Trends and mitigation options of greenhouse gas emissions from the road transport sector in Ecuador
}

\author{
V. Guayanlema ${ }^{1}$, S. Espinoza ${ }^{1}$, A. D. Ramirez ${ }^{2} \&$ A. Núñez ${ }^{1}$ \\ ${ }^{1}$ Instituto Nacional de Eficiencia Energética y Energías Renovables \\ (INER), Ecuador \\ ${ }^{2}$ Escuela Superior Politécnica del Litoral (ESPOL), Ecuador
}

\begin{abstract}
This paper reports the current status of greenhouse gas (GHG) emissions caused by the transport sector in Ecuador and possible mitigation scenarios to reduce them. In the first case, the emissions were quantified by using the IPCC methodology for National GHG Inventories which is based in the quantification of the oil products consumption (TIER 1). The emission estimations have revealed that nearly 33,400 kton $\mathrm{CO}_{2}$-Eq were emitted in 2012. The same year, road transport was identified as the most important sub-sector in terms of $\mathrm{CO}_{2}$ emissions with a contribution of $90 \%$. Road transport emission is followed by aviation and navigation, both not exceeding $10 \%$ of emissions within the transport sub-sector. These pollution trends have grown at a rate of about $6 \%$ (referred to ton of $\mathrm{CO}_{2}$-Eq.). As consequence, several initiatives and research projects have been undertaken with the aim of finding solutions to the current situation in the transport sector. Secondly, an analysis of GHG emissions trends was performed (according to the business as usual scenario) based on historical GHG emission inventories updated to the year 2012. This analysis was designed using the software Long-range Energy Alternative Planning (LEAP). For this purpose, Governmental strategies including measures related to fuel consumption, use of new technologies, political actions such as scrapping of the vehicle that have completed their life cycle, the introduction of hybrid and electric automobiles were considered. Preliminary results of the analysis indicate that political actions like scrapping vehicles and the use of biofuels are the most promising solutions to reduce rising trends of emissions and energy consumption.

Keywords: GHG, mitigation, scenarios, Ecuador.
\end{abstract}




\section{Introduction}

In 2010 the transport sector was responsible for about $31 \%$ of energy demand in Latin America [1]. Nowadays, this sector is one of the main contributors to $\mathrm{CO}_{2}$ emissions in the region; its share increased from $33 \%$ in 1980 to $34 \%$ in 2005 [2]. The situation in Ecuador reflects a similar trend. From 1850 to 1950 energy consumption increased $1.2 \%$ per year on average. During this period, the main energy source was coal. Whereas from 1950 to 2006, the average percentage of energy consumption increased by $3 \%$. Through this time span, both oil and natural gas were the most used energy sources [3]. Both the economic and population growth in developed countries are the main drivers of an unprecedented level of energy consumption per capita [4]. Nevertheless, energy demand in developed nations might be outweighed by developing countries. The cause of this phenomenon is attributed to how rapidly these economies are growing, specially China, India, Brazil, and Mexico [5].

In Ecuador, the transport sector is the biggest consumer of fossil fuels. In 2008, this sector reached $55 \%$ of the total national consumption [3]. The main reason for this issue has been accredited not only to high fossil fuels' subsidies, but also to a low energy consumption compared to transport by other sectors such as residential and industry. During the first six months of 2012, the government spent $\$ 1.6$ Billion in these subsidies [6].

Furthermore, according to reports from the National Institute of Statistics and Census (INEC in Spanish), fleet increased 19\% from 2009 to 2012 [7]. The size of the fleet has not grown steadily. The increase in the number of vehicles comes along with, a higher consumption of fossil fuels. It has been identified that road transport is responsible for the biggest consumption of hydrocarbons. Gasoline has the largest share (44\%), followed by diesel (41\%) [8]. In 2006, the energy sector was responsible for $7 \%$ of the total national GHG emissions [9]. Within the energy sector the transport subsector accounts for $50 \%$ of GHG emissions.

The aim of the present research is to estimate GHG emissions attributed to the transport sector for the last 6 years (2007-2012) and to scheme mitigation measures to be started in 2014. For this endeavor, IPCC methodology will be used to compile and update the National GHG inventories for the transport sector. Furthermore, mitigation scenarios will be created using the Long-range Energy Alternative Planning software-LEAP. The scenarios will help to analyze the feasibility of the desired scenario and the likelihood of implementation of its different elements [10].

\section{Methodology}

\subsection{GHG emission inventories}

In this study the transport sector includes road, rail, air, water transportation. For the GHG emissions estimation, IPCC 1996 Guidelines for National GHG Inventories [11] were used. This methodology was complemented with the 2006 IPCC guide for inventory collection [12]. 
The main data sources were the Agency for Control and Regulation of Hydrocarbons (ARCH in Spanish), and the Transit National Agency (ANT in Spanish). The data collected included rail transport into road transport, for this reason, it was not possible to consider the rail subsector separately.

Given the limitation regarding data availability in the country, Tier-1 (IPCC simple method) [12] was used, following the next equation, according to the IPCC methodology:

$$
\mathrm{CO}_{2} \text { Emission }=\sum_{s j} E_{s j t} * F E_{j}
$$

where $E$ is the consumption of fuel $j$ for sector $s$ for year $t$, and $F E$ is the emission factor for fuel $j[12]$.

The default IPCC emission coefficients have been used for generating the inventories, which is based on an energy value approach for universal acceptability, as heat values of different fuels could be different from one country to another [11].

\subsection{GHG mitigation scenarios}

According to the definition, a scenario is a hypothetical sequence of logical and plausible (but not necessarily probable) events, constructed in order to focus attention on causal processes and decision points [10]. For this case study, we evaluated the actions that have been taken, including possible improvements for the current situation.

The scenarios analyzed realistic and probable measures in a long-term [13] of 30 years [14]. For the development of mitigation scenarios, GHG inventories and macro-economic variables [15] shown in Table 1 were used.

Table 1: Macro-economy’s variables.

\begin{tabular}{|c|c|c|}
\hline Information & Value & Unit \\
\hline Inflation & 4.16 & $\%$ \\
\hline Base year & 2012 & - \\
\hline Population & $14^{*}$ & Millions \\
\hline Population growth rate & 1,419 & $\%$ \\
\hline First year of scenario & 2013 & - \\
\hline GDP per capita & 4,052 & USD \\
\hline Growth rate of GDP per capita & 3.58 & $\%$ \\
\hline
\end{tabular}

SOURCE: INEC, Annual Report 2010 and 2011, Quito, pp. 29-113.

Data regarding population growth rate was taken from the United Nations Population Fund (UNFPA) [16]. 
Table 2: Evolution of population growth rate [16].

\begin{tabular}{|c|c|}
\hline Year & $\begin{array}{c}\text { Growth rate } \\
\text { of population }\end{array}$ \\
\hline 2010 & 1.50 \\
\hline 2015 & 1.32 \\
\hline 2020 & 1.15 \\
\hline 2025 & 0.98 \\
\hline 2030 & 0.82 \\
\hline 2035 & 0.66 \\
\hline 2040 & 0.51 \\
\hline
\end{tabular}

\section{Results and discussion}

\subsection{GHG emissions}

Figure 1 depicts transport $\mathrm{CO}_{2}$ emissions in Ecuador excluding international transportation (air and maritime), which are reported separately. According to the IPCC Guidelines for National Inventories, the difference between total emissions from the energy sector and transport sector are attributed to industry and construction.

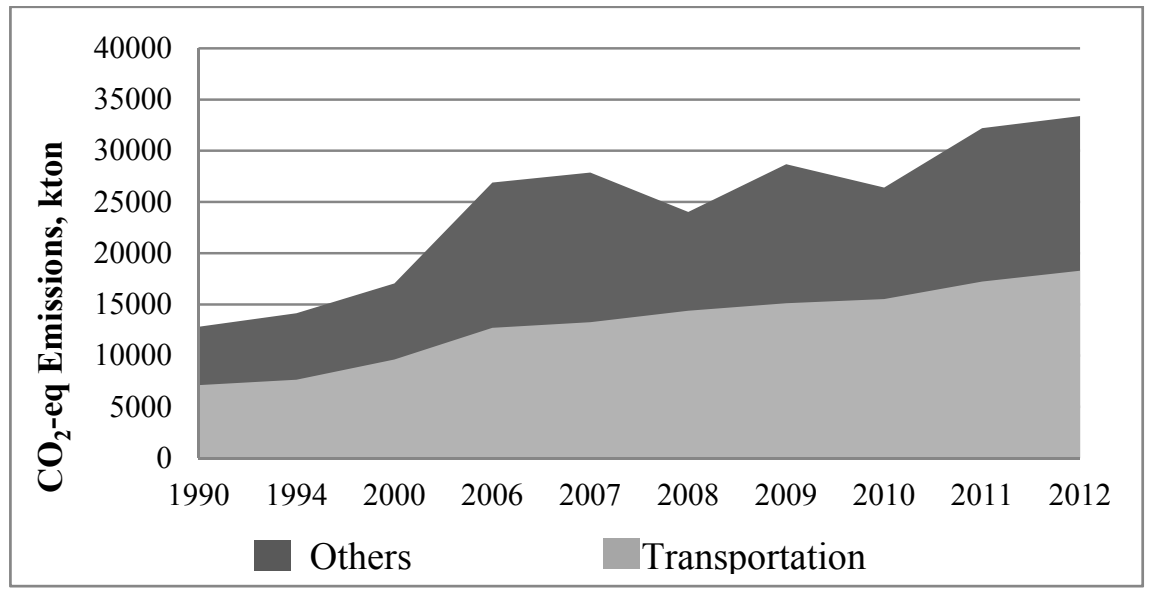

Figure 1: Ecuador's $\mathrm{CO}_{2}-\mathrm{Eq}$ emissions in energy sector including transportation.

Transport is the energy subsector that contributes more than 50\% (18300 kton $\mathrm{CO}_{2}$-eq.) to the total emissions. One of the reasons for this issue is the rapid growth of the fleet, which is a global pattern [17]. In 2007, vehicles registered by ANT reached 920,000 units [18], whereas in 2012, this number was 1,590,000 [7]. 
Table 3: GHG and other emissions from transport in Ecuador, kton.

\begin{tabular}{|c|c|c|c|c|c|c|c|}
\hline Years & $\mathbf{C O}_{\mathbf{2}}$ & $\mathbf{C H}_{\mathbf{4}}$ & $\mathbf{N}_{\mathbf{2}} \mathbf{O}$ & $\mathbf{N O x}$ & $\mathbf{C O}$ & $\mathbf{N M V O C}$ & $\mathbf{S O}_{\mathbf{2}}$ \\
\hline $\mathbf{2 0 0 7}$ & 13,180 & 2.2 & 0.12 & 135 & 772 & 146 & 26 \\
\hline $\mathbf{2 0 0 8}$ & 14,300 & 2.2 & 0.13 & 151 & 762 & 144 & 31 \\
\hline $\mathbf{2 0 0 9}$ & 15,000 & 2.3 & 0.14 & 157 & 813 & 154 & 26 \\
\hline $\mathbf{2 0 1 0}$ & 15,400 & 2.6 & 0.14 & 158 & 947 & 179 & 30 \\
\hline $\mathbf{2 0 1 1}$ & 17,000 & 2.9 & 0.16 & 175 & 1,058 & 199 & 33 \\
\hline $\mathbf{2 0 1 2}$ & 18,100 & 3.1 & 0.16 & 189 & 1,120 & 211 & 34 \\
\hline
\end{tabular}

\subsection{Mitigation options}

\subsubsection{Introduction to hybrids}

The country's vehicle fleet is composed by $6.25 \%$ of hybrid vehicles with an annual growth rate of $1.52 \%$ [19]. "Hybrid vehicles entered the Ecuadorian market in 2009 as a consequence of tax reductions. About 1,400 of these vehicles were sold during the first year. In 2012, 4,500 units were sold" [19]. However, this program stopped due to the lack of control in the size of the engines being introduced in the country, which caused less efficiency in fuel consumption. During the same year, a green tax was established for vehicles with engines over $2,000 \mathrm{~cm}^{3}$ [20]. A vehicle with a $2,000 \mathrm{~cm}^{3}$ internal combustion engine has a consumption of 7 liters of gasoline in a 100 kilometers trip [21].

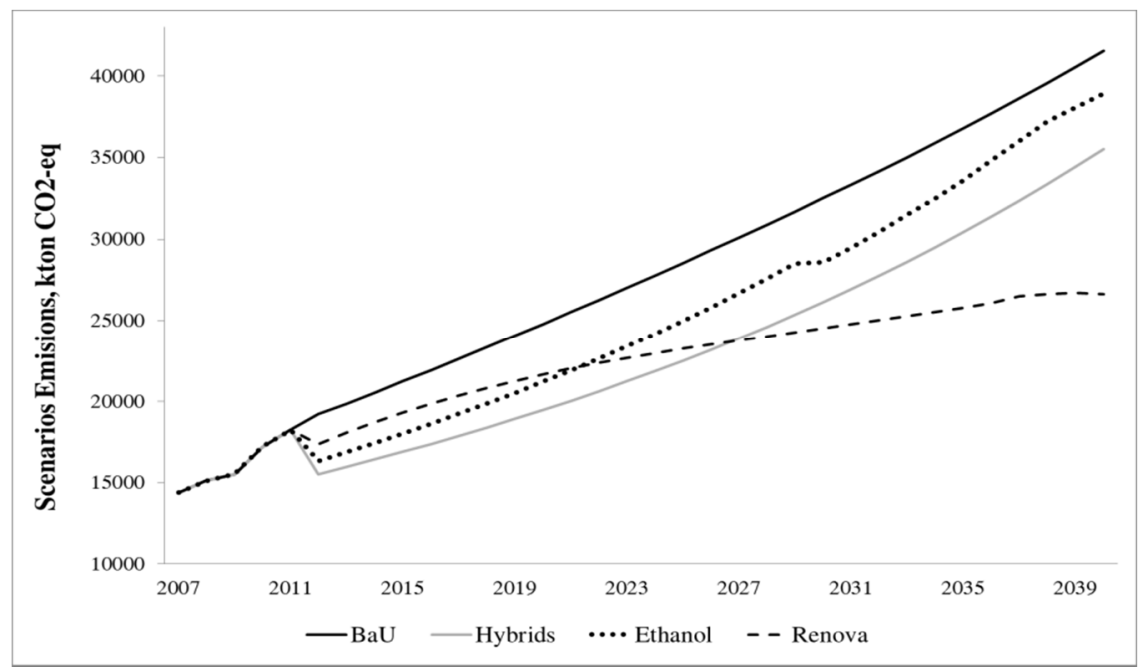

Figure 2: $\quad \mathrm{CO}_{2}$-Eq. Emissions for different scenarios. 
According to the analysis of this scenario developed with the information described in the above paragraph, $\mathrm{CO}_{2}$ emissions decreased $17 \%$ the total emissions to $2040\left(163,900 \mathrm{kton}\right.$ de $\mathrm{CO}_{2}$-eq). It is a significant reduction in terms of GHG, taking into account that the percentage of hybrid vehicles is low. However, better results should be expected, because this technology can prove to be a short-term expedient technology [22].

\subsubsection{Fleet renovation}

The Ecuadorian RENOVA Plan for the transport sector, started in 2008, and its purpose is to take out of circulation obsolete vehicles and replace them with new ones. The result of this initiative was a reduction of $0.89 \%$ in gasoline consumption [23] for light-duty transport. If this plan becomes mandatory, instead of voluntary, for vehicles older than 15 years, it is foreseen that a substitution of $5 \%$ total fleet might be achieved.

With the present vehicle scrapping ordinance, emissions would decrease $26 \%$ (243,900 kton de $\mathrm{CO}_{2}$-eq removed to 2040) in comparison with BAU (Business as Usual) scenario.

In this case, this scenario uses information to RENOVA Plan and the decreases in the life cycle of vehicle according to the law of Ecuador.

The initial budget for the climate mitigation action RENOVA from 2008 to 2010 was approximately $\$ 234,000,000$. During this period of time it was only spent $\$ 35,256,000$ due to the inefficiency in promoting the plan [24]. Nevertheless, the measure saved the country $\$ 15,500,049.57$ in subsidies. It needs to be considered that the mitigation actions not necessarily have to be economically feasible, since the most important factor is the quality of life attained [25].

\subsubsection{Biofuels use}

Since 2010, a 95\% gasoline-5\% ethanol blend is being used in Ecuador [26]. Using Life Cycle Assessment it was determined that "The use of this blend will reduce 8 grams of $\mathrm{CO}_{2}$ emissions per kilometer" [27]. This reduction is equivalent to $4 \%$ of total GHG emissions attributed to gasoline. Annual production of this fuel has grown around $2 \%$, and its use will be translated in a reduction of GHG emissions, equivalent to $10 \%$ (955,600 kton de $\mathrm{CO}_{2}$-eq removed) to 2040 . Nevertheless, the Ministry Coordinator of Production, Employment and Competitiveness hopes to reach a $10 \%$ annual growth by 2015 and change the blend to $80 \%$ gasoline $-20 \%$ ethanol [28].

Considering a simultaneous implementation of all the scenarios studied in the present work, total GHG emissions to 2040 would be reduced by $43 \%$.

Road transport emits significant quantities of $\mathrm{CO}_{2}$ and $\mathrm{CH}_{4}$ (methane) and $\mathrm{NO}_{2}$ (Nitrous Oxide) as a product of incomplete combustion, in addition to ozone gases like $\mathrm{CO}, \mathrm{NO}_{\mathrm{X}}$ and NMVOC. The $\mathrm{CH}_{4}$ emission and $\mathrm{NO}_{2}$ has been the principal focus. These trends have been more impact in the environmental. By the case of hybrids introduction the $\mathrm{CH}_{4}$ emission would be reduced nearly $34 \%$ (only in this assumption). 


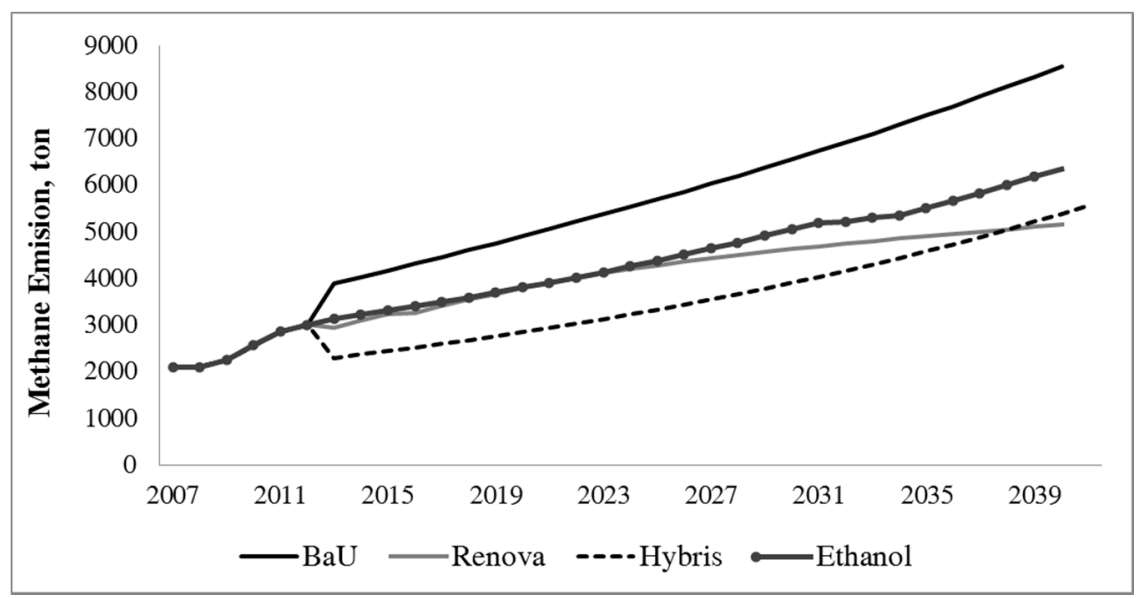

Figure 3: Methane emissions in the transport sector for different scenarios.

Effects of transportation leads to external cost which the impacts on climate change are presently considered the most serious ones [29]. This actions need to be combined on the base of a least cost strategy. The scenarios show a decrease from 1,366,400 kton $\mathrm{CO}_{2}$-eq to 2040. Considering the price of one ton of carbon is $\$ 12$ per ton on average, the cost of this reduction would be about 163 billion dollars. The $60 \%$ of this cost will be financed by the local government whereas the remaining $40 \%$ will be in charge of international organizations.

\section{Conclusions}

Transport sector in Ecuador emitted on average 29,000 kton of $\mathrm{CO}_{2}$ Eq. per year, in the last six years. These emissions represent about $50 \%$ of the energy sector. Road transport was identified as the biggest GHG emitter. The road transport emissions are attributed to the growth rate of the fleet, which is about $8.76 \%$, and causes a high traffic density, efficiency losses, and high fuel consumption.

The GHG emissions in transportation have grown at a rate of about $6.6 \%$ from 2006 to 2012 (referred to kton of $\mathrm{CO}_{2}-\mathrm{Eq}$ ). This fact is in part consequence of the economic growth that the country has experimented since 2006.

Afterwards, the evolution of GHG emissions was determined, mitigation measures for reducing these trends for the next 30 years were considered. These measures are addressed to reduce the effects of climate change. The main focus of the study was road transport, since it's the biggest contributor to GHG emissions. The Ecuadorian government ought to retake the incentive program for the acquisition of hybrid vehicles. The introduction of hybrids would reduce GHG emissions more than $20 \%$ until 2040. 


\section{Acknowledgements}

The authors thank SENPLADES (Secretaría Nacional de Planificación y Desarrollo) and the INER (Instituto Nacional de Eficiencia Energética y Energías Renovables).

\section{References}

[1] AEI, "Outlook for Energy," in Outlook for Energy, 2013th ed., USA, 2013.

[2] G. R. Timilsina and A. Shrestha, "Factors affecting transport sector CO 2 emissions growth in Latin American and Caribbean countries : An LMDI decomposition analysis," Int. J. Energy Res., vol. 33, no. December 2008, pp. 396-414, 2009.

[3] M. Castro, Hacia una matriz energética diversificada en Ecuador. Quito: Centro Ecuatoriano de Derecho Ambientaal, 2011, p. 128.

[4] A. Grübler, "Energy Transitions," in Encyclopedia of Earth, Clevenland, Ed. Washington D.C., 2008.

[5] The World Bank Group, "World Development Indicators," World Development Indicators: Traffic and congestion, 2012. [Online]. Available: http://wdi.worldbank.org/table/3.13.

[6] Banco Central del Ecuador, "Reporte del Sector Petrolero III trimestre de 2012," 2012.

[7] INEC, “Anuario de Transporte 2012," Quito, 2013.

[8] ARCH, "Reporte de Estadísticas de Hidrocarburos," Quito, 2013.

[9] Cácerez and Núñez A., "Inventario Nacional de Gases del Efecto de Invernadero en Ecuador 1990, 1994, 2000, 2006," Quito, 2010.

[10] Y. Shiftan, S. Kaplan, and S. Hakkert, "Scenario building as a tool for planning a sustainable transportation system," Transp. Res. Part D Transp. Environ., vol. 8, no. 5, pp. 323-342, Sep. 2003.

[11] IPCC, Revised 1996 IPCC Guidelines for National Greenhouse Gas Inventories, First. Cambridge: Institute for Global Environmental Strategies, 1997, p. 96.

[12] IPCC, Good Practice Guidance and Uncertainty Management in National Greenhouse Gas Inventories. Intergubermental Panel on Climate Change, IPCC, 2006.

[13] R. A. Smith, D. R. A. Vesga, A. I. Cadena, U. Boman, E. Larsen, and I. Dyner, "Energy scenarios for Colombia: process and content," Futures, vol. 37, no. 1, pp. 1-17, Feb. 2005.

[14] L. M. Kamp, "Socio-technical analysis of the introduction of wind power in the Netherlands and Denmark," Int. J. Environ. Technol. Manag., vol. 9, no. $2 / 3$, p. $276,2008$.

[15] C. G. Heaps, "Long-rate Energy Alternatives Planning (LEAP) system." Energy Community, Somerville, 2012.

[16] Embargoed Until, "World Population Prospects The 2012 Revision," New York, 2013. 
[17] J. De Vos, B. Derudder, V. Van Acker, and F. Witlox, "Reducing car use: changing attitudes or relocating? The influence of residential dissonance on travel behavior," J. Transp. Geogr., vol. 22, pp. 1-9, May 2012.

[18] INEC, "Anuario de Transporte 2007," Quito, 2008.

[19] AEADE, "Anuario 2012," Asociación de Empresas Automotrices del Ecuador, Quito, p. 93, 2013.

[20] O. Gamboa, "Plan de Comercialización de Sistemas Híbridos en el Valle de lso Chillos en la ciudad de Quito-Ecuador," Iniversidad Internacional del Ecuador, 2012.

[21] F. Xavier and C. Mondragón, "Análisis de Rendimiento, Consumo y Emisiones Generadas por los Vehículos Híbridos " Proyecto," Escuela Politécnica del Ejercito, 2011.

[22] K. Kojima and L. Ryan, "Transport Energy Efficiency," International Energy Agency, París, p. 60, 2010.

[23] ANT, "Plan Renova," Enero, 2013.

[24] C. Villamarín, "Evaluación Financiera del Plan Renova vehicular implementado por la CFN y la propuesta de ampliación dirigida al sector de transporte privado particular," Escuela Politecnica del Ejercito, 2013.

[25] J. D. Jenkins, "Political economy constraints on carbon pricing policies: What are the implications for economic efficiency, environmental efficacy, and climate policy design?," Energy Policy, pp. 1-11, Mar. 2014.

[26] R. Gomelsky, B. Chiliquinga, and F. Figueroa, "Politica Nacional de Biocombustibles en el Ecuador," Quito, 2010.

[27] H. Cabla and C. Lechón, "Análisis del Ciclo de Vida de los Combustibles Alternativos para el transporte," Ministerio del Ambiente, Madrid, p. 72, 2005.

[28] F. A. Figueroa, "Tablero de comando para la promoción de los biocombustibles en Ecuador," Santiago de Chile, 2008.

[29] A. Musso and W. Rothengatter, "Internalisation of external costs of transport - A target driven approach with a focus on climate change," Transp. Policy, vol. 29, pp. 303-314, Sep. 2013. 